
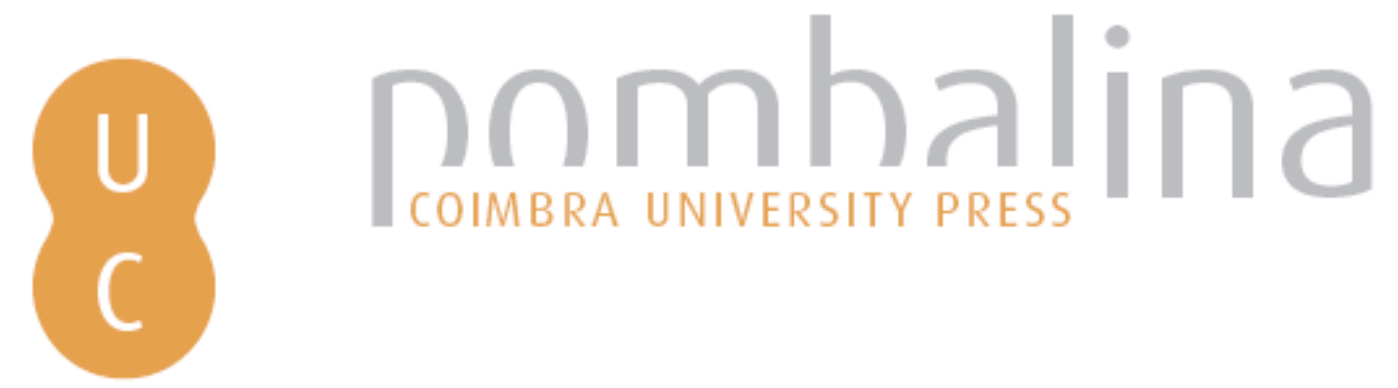

\title{
A alimentação dos expostos através da memória sobre a preferência do leite de vaccas (1812), de José Pinheiro de Freitas Soares (1769-1831)
}

\author{
Autor(es): $\quad$ Soares, Kevin Carreira
}

Publicado por: Imprensa da Universidade de Coimbra

URL

persistente: URI:http://hdl.handle.net/10316.2/45233

DOI: $\quad$ DOI:https://doi.org/10.14195/978-989-26-1721-3_6

Accessed : $\quad$ 26-Apr-2023 09:19:33

A navegação consulta e descarregamento dos títulos inseridos nas Bibliotecas Digitais UC Digitalis, UC Pombalina e UC Impactum, pressupõem a aceitação plena e sem reservas dos Termos e Condições de Uso destas Bibliotecas Digitais, disponíveis em https://digitalis.uc.pt/pt-pt/termos.

Conforme exposto nos referidos Termos e Condições de Uso, o descarregamento de títulos de acesso restrito requer uma licença válida de autorização devendo o utilizador aceder ao(s) documento(s) a partir de um endereço de IP da instituição detentora da supramencionada licença.

Ao utilizador é apenas permitido o descarregamento para uso pessoal, pelo que o emprego do(s) título(s) descarregado(s) para outro fim, designadamente comercial, carece de autorização do respetivo autor ou editor da obra.

Na medida em que todas as obras da UC Digitalis se encontram protegidas pelo Código do Direito de Autor e Direitos Conexos e demais legislação aplicável, toda a cópia, parcial ou total, deste documento, nos casos em que é legalmente admitida, deverá conter ou fazer-se acompanhar por este aviso.

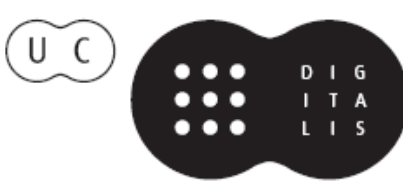


Carmen Soares

Gilene da Silva Gomes Ribeiro

(coords.)

\section{Mesas \\ LUSO-BRASILEIRAS}

\section{ALIMENTAÇÃO, SAÚdE \& GULTURA}

\section{VOLUME I}

IMPRENSA DA UNIVERSIDADE DE COIMBRA COIMBRA UNIVERSITY PRESS

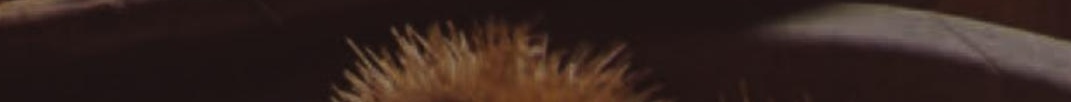




\title{
A alimentação dos expostos através da MEMÓRIA SOBRE A PREFERENCIA DO LEITE DE VACCAS (I 8 I 2 ), DE José Pinheiro de Freitas Soares (i $769^{-1} 83$ I $)^{\mathrm{I}}$
}

\section{(The feeding of foundlings through the memória sobre a preferência do leite de vaccas (1812), of José Pinheiro de Freitas Soares (1769-1831))}

\author{
Kevin Carreira Soares \\ Universidade de Coimbra \\ Faculdade de Letras \\ (kevincasoares@gmail.com)
}

\begin{abstract}
RESUMO: Durante o século XIX, os expostos tornaram-se um assunto central para toda a sociedade. O crescente número de abandonos, até meados deste século, promoveu o surgimento de vários escritos que, para além do debate sobre a legitimidade da Roda, procuraram soluções para obviar as elevadas taxas de mortalidade na generalidade destas instituições. Foi assim que, sob o novo primado das ciências médicas e de higiene, fortemente associadas a novos paradigmas científicos, alguns autores procuraram promover novos hábitos e cuidados a ter com as crianças que ali eram deixadas. A partir de um desses autores - José Pinheiro de Freitas Soares - é objetivo lançar um olhar sobre o que a cultura erudita da época considerava como mais correto para a alimentação dos expostos, em alternativa ao leite materno que, por falta de amas-de-leite, nem sempre lhes era possível assegurar. Ao mesmo tempo, foi dada alguma atenção às práticas e utensílios que o autor permite conhecer, partindo da memória sobre a preferencia do leite de vaccas ao leite de cabras para o sustento das crianças... da sua autoria.
\end{abstract}

PAlavRAS-ChAve: História da alimentação, expostos, Roda de expostos, infância, Academia Real das Ciências.

ABSTRACT: During the nineteenth century, foundlings became a major concern for whole society. Their growing number until the middle of the century, led to the emergence of various writings that promoted not only the debate about the

1 Para a construção desse texto pude contar com a colaboração de duas colegas, Dr. ${ }^{a}$ Rute Preto e Dr. ${ }^{a}$ Cátia Serena, recém-formadas em medicina, que comigo o trabalharam na parte que se ligava com o consumo de alimentos e utensílios recomendados. Foi objetivo alcançar capacidade crítica mais consistente e fundamentada, em relação à (in)adequação das espécies, quantidades e práticas apontadas. Pelas valiosas pistas e pela disponibilidade fica o reconhecido agradecimento. Pude beneficiar ainda da leitura atenta de Beatriz Cabral, na primeira versão dessa comunicação, e de Luís Gonçalves e Pedro Sebastião, numa versão mais avançada. A eles, bem como ao referee que avaliou este texto, agradeço os valiosos comentários. 
legitimacy of the foundling wheel, but also sought solutions to decrease the high mortality rates of these institutions. Under the new primacy of medical science and hygiene, some authors became strongly associated with new scientific paradigms, in order to improve the healthcare of those who were left there. From one of these authors - José Pinheiro de Freitas Soares - it is objective to explore what the erudite culture of that century considered more correct for the feeding of abandoned children in alternative of breastfeeding. At the same time, it was given attention to some practices and tools, which this author allows to know, based on the "memória sobre a preferencia do leite de vaccas ao leite de cabras para o sustento das crianças" of his authorship.

KEYWORDS: Food history, foundlings, Foundling wheel, childhood, Royal Academy of Sciences.

No contexto da história da alimentação - tema geral do presente colóquio - é objetivo dessa comunicação propor uma breve reflexão em torno desse tema, relacionando-o com os expostos, através de uma memória publicada pela Academia Real das Ciências de Lisboa, em 1812, intitulada Memoria sobre a preferencia do leite de vaccas ao leite de cabras para o sustento das crianças, principalmente nas grandes casas dos expostos; e sobre algumas outras matérias, que dizem respeito á criação delles, da autoria de José Pinheiro de Freitas Soares.

Como é conhecido, a assistência à infância abandonada foi um tema central em Portugal, particularmente durante o século XIX, quando o número de expostos atingiu números ímpares no contexto europeu. Neste século, a assistência aos enjeitados absorveu uma parte significativa dos orçamentos das Juntas Gerais dos distritos e das Câmaras Municipais, sendo alvo de diversas medidas que procuravam diminuir o número de abandonos ${ }^{2}$. Ao mesmo tempo, as perturbadoras taxas de mortalidade, as precárias condições de muitos estabelecimentos e o tratamento negligente conferido aos enjeitados por muitas amas, estiveram na origem de diversas medidas legislativas e tratados, entre outros escritos, que procuravam alterar essa situação. A título

2 A título de exemplo, a orçamento da Junta Geral do Distrito de Leiria para o ano económico de 1860/1, reservou $8572 \$ 000$ dos $10442 \$ 902$ do total, para sustentação de expostos e subsídios a mães pobres, ver ADLra - Fiscalização e Fiscalidade. Expostos do Distrito de Leiria 1835 - 1877. Orçamento do distrito para o ano económico de 1860 a 1861, não numerado. No caso da Câmara Municipal de Porto de Mós, distrito de Leiria, entre 1839/40 e 1869/0, o peso da despesa diretamente relacionada com expostos representou, em média, 43\%, ver AHMPM Atas de Vereação da Câmara Municipal de Porto de Mós 1839-1842, fl. 69v.-70, 122; 1842-1843, fl. 37-37v., 70v.-71, 72-72v.; 1843-1848, fl. 62-62v., 79v.-80v., 97-98v., 117v.-118; 1848-1853, fl. $12-14$ v., 25v.-26v., 98v.-99v., 128-129, 175v., 187v.-188; 1853-1857, fl. 10v.-11, 64v.-65v., 99v.-100, 119v.-120, 152v.-153v., 182-182v.; 1857-1864, fl. 24-24v., 70-70v., 93v.-94v., 127v., 163-164, 186-187v.; 1864-1875, fl. 19v.-20; 44v.-45, 72-72v., 124v.-125v., 130v.-131, 155v.$-157 \mathrm{v}$. e $175 \mathrm{v} .-176 \mathrm{v}$. 
de exemplo, veja-se que entre 1803 e 1819, das 6145 crianças deixadas na Roda de Coimbra, 4149 (67,50\%) morreram antes de completar a criação. Nesta Roda, nos anos mais dramáticos, o número de mortos chegou aos $89,4 \%$ (1813 - 471 morreram em 527 entradas) e 84,10\% (1811 - 285 morreram em 339 entradas) $)^{3}$.

Com a afirmação do Estado Polícia e sob o primado crescente das ciências médicas, essa produção intensificou-se, a par da discussão em torno da legitimidade da Roda e do abandono. Foi assim que surgiram diversos textos cuja finalidade era a de contrariar hábitos considerados erróneos ou dar resposta a problemas concretos, como a falta de amas-de-leite. Entre estes esteve José Pinheiro de Freitas Soares que, na obra em análise, defendeu a preferência pelo recurso ao leite de vacas, em alternativa ao de cabra, sempre que o número de amas se apresentava insuficiente para amamentar todos os expostos. Esse texto principiou por ser apresentado em conferência no Congresso dos Professores de Medicina, em junho de 1812. Em novembro desse ano, a memória sobre a preferencia do leite de vaccas ao leite de cabras nas grandes Casas dos Espostos, foi considerada "muito digna de publicar-se", com a proteção e privilégios da Academia Real das Ciências".

O texto que se segue centra-se nesta obra e nele se destacarão as rotinas e os consumos defendidos pelo autor, bem como a identificação dos comportamentos considerados errados ou adequados. Com este intuito, o trabalho foi estruturado em três partes distintas. Na primeira pretende dar-se a conhecer alguns dados biográficos de José Pinheiro de Freitas Soares, bem como o contexto científico e cultural em que preparou esse Tratado Médico; na segunda, serão apresentados os alimentos e as quantidades prescritas. Finalmente, na última parte, serão referidos os utensílios relacionados com a amamentação.

\section{O Autor E O SEU TEMPO}

José Pinheiro de Freitas Soares, filho de António Pinheiro e Josefa Luísa, nasceu a 2 de maio de 1769, em Águeda, Comarca de Aveiro, Bispado de Coimbra $^{5}$. Frequentou a Universidade de Coimbra, onde se matriculou, pela

${ }^{3}$ Ver Lopes 2000: vol. 1, 318-319. São numerosos os estudos sobre este assunto. Seguiram-se de mais perto Lopes 1984: 119-176; Roque 1982; Sá 1995; Sá 1992: 75-89 e Soares 2015.

${ }^{4}$ Cf. Memoria sobre a preferencia - Soares 1812: 3.

5 "Em os sete dias do mes de Mayo de mil e setecentos sessenta, e nove Baptisei solemenemente e pus os Santo Olios a Joze filho Legitimo de Antonio Pinheiro, e sua mulher Josefa Luiza de Jezus deste Lugar, e freguesia de Agueda do Bispado de coimbra, [...] nasceo aos dois dias do dito mes, e anno, he neto, pella parte Paterna de Joam Pinheiro, e de Luiza Maria de Oliveira, e pella Materna de Joze Soares e de sua mulher Roza Maria todos deste Lugar e freguesia forão Padrinhos, Joze Ozorio Pinto de Almeida da quinta do Morangal freguesia de 
primeira vez, em 21 de outubro de 1788, em Filosofia. Depois de frequentados os anos obrigatórios nesta disciplina e em matemática, conforme disposto nos novos estatutos de 1772 , recebeu o grau de bacharel em medicina, no dia 31 de julho de $1797^{6}$. Concluída a sua formação, regressou a Aveiro, onde exerceu o ofício de médico.

Em 18 de abril de 1804, foi objeto de denúncia feita à Inquisição, numa altura em que esse tribunal se encontrava já com fraca capacidade de intervenção sobre a sociedade. Nesta, o delator acusou-o de "lêr livros prohibidos, e igualmente que naõ acreditava na immortalidade d'Alma, que era Pedreiro livre, e sobre todas estas coizas fez seus discursos com bastante liberdade"7. Esse tipo de acusações foi frequente, por estas décadas em que a Inquisição concentrava esforços em reprimir as ideias originárias da Revolução Francesa, frequentemente associadas com a frequência de casas maçónicas, em alinhamento com os interesses maiores da Coroa. A passagem pela Universidade de Coimbra, numa altura em que a comunidade estudantil se mostrava hostil a muitos dogmas tradicionais e recetiva à discussão de autores e obras heréticos, aos olhos da Inquisição, deverá ter estado na base dessa denúncia a José Pinheiro de Freitas Soares. Pese embora a acusação, não se conhece qualquer andamento ao caso, como foi frequente nesta cronologia ${ }^{8}$.

Em 5 de maio de 1826, recebeu a nomeação para médico honorário da Câmara Real de D. João VI ${ }^{9}$. Foi ainda físico-mor do Reino, membro

Espinhel, e madrinha Donna Anna Eugenia de Figueiredo Bandam Donzela filha de Diogo Henrique Coelho assistente neste mesmo lugar e freguesia foram testemunhas Manoel Dias da Cruz e Manuel de Matos ambos deste mesmo lugar e freguesia”, cf. AUC - Certidôes de Edade, 1772-1883, fl. 95 e $95 \mathrm{v}$.

6 Sobre a reforma do ensino operada a partir dos estatutos pombalinos de 1772, ver Fonseca 2014: 49-78. Foi possível encontrar o registo de matrícula no $1 .^{\circ}$ ano de filosofia, em 1788; no $1 .^{\circ}$ ano de matemática em 1789; no $2 .^{\circ}$ ano de matemática em 1790 e no $3 .^{\circ}$ ano de Filosofia em 1791, ver, respetivamente, AUC - Matrículas. 1788/89. Matriculas em Filozofia, fl. 14; Matriculas. 1789/90. Matrículas em Matemática, fl. 17v; Matriculas. 1790/91. Matrículas em Matemática, fl. 41v e Matrículas. 1791/92. Matrículas em Filozofia, fl. 51v. Do ano de 1792 até ao ano de 1796, José Pinheiro de Freitas Soares matriculou-se nos cinco anos necessários para se formar em medicina, ver AUC - Matrículas. 1792/93, fl. 121v.; Matrículas. 1793/94, fl. 155; Matrículas. 1793/94, fl. 155; Matrículas. 1795/96, fl. 201; Matriculas. 1796/97, fl. 211v. O Diploma de Bacharel em Medicina, reconhecendo-lhe a aprovação no dia 31 de julho de 1797, encontra-se em anexo.

7 O processo estava dirigido contra vários indivíduos em simultâneo, ver ANTT - Tribunal do Santo Ofício, Inquisição de Lisboa, proc. 17193. Encontrou-se outro processo no mesmo arquivo, do ano de 1821, que não foi possível consultar por se encontrar em mau estado, segundo informação dos técnicos da instituição, ver ANTT - Feitos Findos, Processos-Crime, Letra M, mç. 71, n. ${ }^{\circ} 79$, cx. 157.

8 Ver Paiva 2013: 383-400.

9 José Pinheiro de Freitas Soares recebeu a nomeação para médico efetivo da Câmara Real, em 5 de maio de 1826. Seguindo a fonte "hey por bem, e me praz fazer merce a Joze Pinheiro de Freitas Soares Medico Honorario da Minha Real Camara de o tornar[?] por efetivo della com $100 \$ 000$ de ordenado por anno pagos pelo Thezoureiro de Minha Caza como tem os mais 
da Junta de Saúde Pública, sócio da Académica Real das Ciências, entre outros cargos de natureza variada ${ }^{10}$. Foi autor de várias obras sobre o tema da higiene pública e da polícia médica, entre as quais, o Tratado de polícia, na qual se comprehendem tidas as materias que podem servir para organizar um regimento de policia de saude..., que tem recebido alguma atenção por parte de diversos investigadores, e uma memoria sobre a preferencia do leite de vaccas ao leite de cabras para o sustento das crianças, principalmente nas grandes casas dos expostos, e sobre algumas outras materias que dizem respeito à creação d'elles, obra em análise no presente trabalho.

Os dados biográficos permitem antever o enquadramento ideológico desse autor. Fortemente arreigado aos princípios das luzes, Freitas Soares foi um dos autores mais destacados entre os defensores e promotores do Estado Polícia, ideologia em afirmação desde o consulado pombalino, e que o liberalismo impôs como central nas políticas adotadas ${ }^{11}$. Como o próprio sustentou: "Esta Sciencia [da policia] [...] abrangendo muitos, e varios objectos, toca tambem aquelle de conservar a saude do homem na sociedade, e de lhe prolongar a vida; a fim de augmentar a população, que he a primeira fonte da riqqueza Nacional"12. Note-se a ligação direta entre a prática médica e o poder político. Era obrigação do Estado criar normas e disciplinar os indivíduos na defesa do interesse económico que uma população mais numerosa e saudável podia gerar, novamente, em favor do Estado ${ }^{13}$. Apresentado o contexto da obra, importa entrar no seu conteúdo. É o que se seguirá.

\section{OS TEMPos E OS ALIMENTOS}

Pelo título da obra, perceciona-se que o autor fez uma apologia da utilização do leite de vaca ao leite de cabra nas grandes casas de expostos, por serem estas que, com maior frequência, careciam de amas a quem entregar os recém-chegados. $\mathrm{Na}$ verdade, a questão da alimentação à infância abandonada foi alvo de grande atenção, na dinâmica cultural acabada de traçar. Neste contexto, as crianças deixadas nas Rodas tornaram-se uma espécie

Medico da Minha Real Camara”, cf. ANTT - Registo Geral de Mercê, D. João VI, liv. 22, fl. 52.

${ }^{10}$ Ver Silva 1860: tomo V, 103 e Silva 1885: tomo XIII, 170-171.

11 Ver Lopes 2008: 131-134 e Lopes 2010: 123-142.

12 Cf. Tratado de Policia Medica - Soares 1818: 1. Para uma abordagem comparativa sobre os tratados da Polícia, as suas contaminações e influências e a sua implicação no surgimento de novos paradigmas médicos, ver Subtil e Vieira 2012: 179-187.

13 O tema é complexo e exige uma explanação que não é possível fazer aqui. Para uma análise mais abrangente destas matérias e do seu contexto, ver Pereira e Pita 1993: 437-559 e Braga 2001: 127-163. 
de "crianças cobaias" na experimentação de novas práticas e alimentos que, tantas vezes, se demonstraram insuficientes ou negativos ${ }^{14}$.

O problema da falta de amas-de-leite já tinha sido objeto de alguma legislação, em décadas anteriores. Exemplo disso é o alvará da Intendência Geral da Polícia, de 31 de janeiro de 1775, no qual se autorizou a redução do aleitamento de 18 para 12 meses, ou menos em caso de necessidade. Foi também em finais do século XVIII que vários autores defenderem a possibilidade de recorrer ao leite de cabra, tendo em conta as carências absolutas de alimento nas grandes Rodas, em algumas épocas. Seguindo de perto as ideias e práticas da Europa Iluminada e tendo em conta várias experiências efetuadas em algumas Rodas do reino, Pina Manique, Intendente Geral da Polícia, aprovou a aplicação do leite de cabra, em Montemor-o-Velho e em Montemor-o-Novo, em 1799. Seguindo as instruções dada pelo Intendente, a sua aplicação devia acompanhar-se de uma rigorosa observação e recolha de resultados ${ }^{15}$.

Os relatórios recebidos foram positivos. Por um lado, a facilidade em mover e manter o animal tornava-o mais apetecível para as Rodas e, por outro, as observações suportavam a sua utilização, uma vez que as crianças pareciam reagir bem ao leite desses animais. Data de 5 de julho de 1801, o aviso geral que declarou que era seguro recorrer ao leite de cabra e que essa prática se podia adotar em todo o reino. Pina Manique garantiu mesmo que o próprio animal dava sinais de felicidade após servir de base para alimentação, "porque estas [as cabras] passadas que sejão as primeiras vezes [em que foram utilizadas para dar leite aos expostos], espontaneamente procurarão aqueles para lhes extrahirem o leite" 16 .

Neste contexto, a obra de José Pinheiro de Freitas Soares tinha o propósito de colocar em causa essa medida, numa altura em que uma parte da sociedade debatia a segurança do leite de cabra. Para o autor, o leite de cabra estava a contribuir para aumentar a mortalidade dos expostos, devido à sua maior pobreza nutritiva. Do ponto de vista económico, a cabra apresentava também desvantagens em relação à vaca, tendo em conta a relação entre as despesas de sustento e o número de crianças que cada animal podia alimentar ${ }^{17}$. A importância desse assunto e a centralidade desses debates sai reforçada pelo facto de, no mesmo ano, Joaquim Fragoso Siqueira ter publicado outra obra,

14 Ver Sá 1987: 30-31. A expressão é de Isabel Drumond Braga e Paulo Drumond Braga em Braga e Braga 2012: 149-168 (expressão dos autores na p. 162).

15 Ver Abreu 2013: 277-278.

16 Apud Abreu 2013: 279.

17 O autor explora as razões pelas quais manter vacas era mais rentável do que manter cabras, tópico que não foi abordado com profundidade no presente texto, por afastamento ao tema geral em apreço, ver Memoria sobre a preferencia - Soares 1812: 50-53. Laurinda Abreu explorou brevemente a contabilidade feita pelo autor em Abreu 2013: 281. 
fazendo a apologia do leite de cabra em detrimento do de ovelha, sugerindo até a substituição definitiva das amas externas pelo recurso ao leite caprino ${ }^{18}$. Não sendo este o trabalho em análise, reforce-se que o tratado de Freitas Soares integrou um debate mais alargado. Note-se ainda que a existência de múltiplos trabalhos fazendo a defesa de práticas alimentares distintas e relatando diversos tipos de experiência, remete para um universo em que as práticas alimentares não eram homogéneas.

Entrando agora com maior pormenor no conteúdo da obra, importa assinalar que uma das ideias repetidamente referida resulta da consciência de que o melhor alimento para os recém-nascidos era o das suas mães, "poisque na generalidade nenhum outro Leite então convem ao estado das suas faculdade digestivas, senão aquelle que a Natureza lhes concedeo". Nesta escala, o leite-das-amas constituiu a forma de remediar a falta das progenitoras. $\mathrm{O}$ leite dos animais era ainda mais estranho aos expostos, pelo que a sua administração se devia fazer apenas em caso de necessidade absoluta ${ }^{19}$. Assim, no caso de ser necessário recorrer a espécies animais para alimentar os expostos, essa substituição não devia ter lugar antes do fim do terceiro mês. Caso fosse indispensável fazê-lo antes desse tempo, aconselhou que o leite fosse:

[...] cortado com agoa, a fim de o tornar mais fluido, e leve; reduzindo-o desta fórma á consistencia daquelle, que fornece o peito materno em os primeiros dias depois do parto; pouco a pouco irá diminuindo a porção de agoa, até chegar a dar-lho puro ${ }^{20}$.

Nos primeiros 15 dias de vida devia manter-se a proporção de $1 / 3$ de água; nos 15 dias seguintes, 1/4 de água; no segundo mês, 1/8, e, no terceiro

18 Segundo Joaquim Fragoso Siqueira "o leite de Cabra he melhor que o de Ovelha: e he um excellente alimento para as Creanças. As cabras consentem que as Creanças as mammem: e poderiaõ ser de grande soccorro nas Casas dos Expostos, evitando-se assim os gastos, e perigos das Amas, sustentando-se as Cabras necessarias para isto com prados artificiaes", Memoria sobre a creação-Siqueira 1812: 144, nota 1.

${ }_{19}$ Cf. Memoria sobre a preferencia - Soares 1812: 8. Apoiando-se em Ballexserd (1726-1774), o autor registou mesmo "que os filhos, que não são amammentados por Mulheres, não são tão gordos, nem tão corados, nem tão robustos". Conclui: "Tudo isto porém só prova, que o methodo natural de sustentar as Crianças he preferivel ao methodo artificial”, cf. idem: 16. Mais adiante, sobre a necessidade de regular a quantidade de leite, registou que esse cuidado devia ser maior no caso de se tratar do leite de amas (e não da mãe), dado que, "ainda no caso de gozarem todas as qualidades fysicas, e moraes, que caracterizão as boas Amas [...] jámais darão hum Leite, semelhante e qualidades ao leite das mãis, que he preparado pelos cuidados, e leis da Natureza”. Nesta escala, o leite dos animais era ainda mais estranho à criança, devendo ser regulado com grande cuidado, para diminuir os efeitos negativos, cf. idem: 22. É incontestável que o leite das mães é melhor que qualquer outro, por vários fatores, entre estes, o reforço aprimorado do sistema imunológico, pela maior proximidade genética entre a mãe e o recém-nascido.

${ }^{20}$ Cf. Memoria sobre a preferencia - Soares 1812: 17. 
mês, $1 / 12$ de água. Dessa altura em diante, sendo a consistência do leite materno semelhante ao da vaca, podia dar-se puro $^{21}$. Deve notar-se, aliás, a clara consciência da evolução das propriedades do leite ao longo da amamentação.

Sendo essa obra redigida no contexto da afirmação do ideário iluminista, assente na experimentação e na observação dos seus resultados, o autor justificou a escolha através de vários vetores como o peso do leite, a sua consistência e composição e o seu comportamento face à exposição ao ar. Estes dados foram suportados por estudos de diversos autores como Antoine-Augustin Parmentier (1737-1813) e Nicolas Deyeux (1745-1837) que diz terem "sobre as differentes especies de Leites, a analyse a mais exacta, que até hoje conhecemos" ${ }^{22}$. Para além destes, foi possível encontrar referências a Louis Jacques Thénard (1777-1857), Antoine François de Fourcroy (1755-1809) e Jean Vauquelin (1728-1772), no que à observação do leite diz respeito. Após a leitura dos resultados desses estudiosos, a escolha de Freitas Soares advinha da certeza de que o leite de vaca seria "o mais analogo ao leite de peito e suas qualidades" 23 .

Apesar da sensibilidade para muitas das questões relacionadas com os primeiros meses de vida de um ser humano, nem sempre o conhecimento adquirido conduzia às melhores sugestões. Referindo-se às elevadas propriedades tóxicas das primeiras fezes de um recém-nascido, o autor chegou a recomendar que não fosse dado leite nos momentos imediatos à entrada do exposto na Roda, no caso de se tratarem de recém-nascidos, como sucedia na maioria dos casos. Em alternativa, para as primeiras 12 ou 24 horas, recomendou um "cozimento de ameixas com mel, ou agoa com mel, ou agoa com assucar, e muito melhor o mel misturado com soro de Leite", escolha que justificou por ser "primeira necessidade fazer evacuar, antes de começarmos a alimenta-los" devido ao excesso de bile e de outras substâncias, no intestino das crianças. A conceção médica está certa, porém, a recomendação, de nenhum modo se devia seguir ${ }^{24}$.

Após este período, podia começar a dar-se o leite das amas ou, em alternativa, o leite de vaca. Como se nota por vários excertos já referidos, Freitas Soares herdou ainda a conceção, em declínio desde o início do século XVIII, de que o leite materno tinha menor qualidade nutritiva nos primeiros dias após o parto, o que promovia com frequência a procura de outras mulheres

${ }^{21}$ Ver Memoria sobre a preferencia - Soares 1812: 40.

22 Cf. Memoria sobre a preferencia - Soares 1812: 13.

23 Note-se, porém, que o autor registou que o leite de égua ou de burra seria, mesmo assim, preferível ao leite de vaca, escolha fundada no conhecimento dos autores referidos. Esta hipótese não era viável devido à impossibilidade de produzir leite desses animais em quantidade suficiente para alimentar todos os expostos, ver Memoria sobre a preferencia - Soares 1812: 8-9.

${ }^{24}$ Cf. Memoria sobre a preferencia - Soares 1812: 39. 
para alimentar os recém-nascidos ${ }^{25}$. De facto, o leite materno apresenta características muito peculiares nos dias imediatos ao nascimento de uma criança. Porém, a sua administração é de grande importância para o bom desenvolvimento das crianças ${ }^{26}$.

Este não é, aliás, o único caso em que se nota uma certa ambiguidade entre as velhas conceções médicas e a novos avanços. Referindo-se à teoria galénica dos humores, em declínio na Europa ilustrada desde os fins do século XVIII 27 , Freitas Soares não deixou de apontar: "Não posso todavia esquecer-me neste lugar da opinião daquelles, que, pertendendo aperfeiçar a Especie Humana, se decidem para a escolha do Leite sómente pelo genio, e caracter do animal". Recorrendo a Jacques Bellexserd (1726-1774), referiu, por exemplo, a preferência do leite de cabras "aos Povos do Norte, que são sombrios, o Leite de cabras, animaes dotados de vivacidade, e alegres; aos Italianos, que são engenhosos, e espertos, o Leite de vaccas, ánimaes mansos, e vagarosos”. Em linha com o declínio destas teorias, conclui, afirmando que essa circunstância nunca devia sobrepor-se à necessidade de escolher o mais semelhante ao materno, único modo de gerar adultos robustos ${ }^{28}$.

Sobre o período e o número e o horário das refeições, Freitas Soares sustentou uma regulação bastante rígida, segundo a idade e a condição física das crianças, e advertiu para a necessidade de não interpretar o choro como uma necessidade de leite, distinguível das demais necessidades, "pelo vasio, e molleza do ventre, e por ellas [as crianças] levarem frequentes vezes as mãos á boca" ${ }^{29}$. Para o efeito, recomendou um calendário de alimentação que devia ser estritamente seguido. Essa escolha foi justificada pela necessidade de manter um grande controlo nas grandes casas e devido às especificidades da amamentação $\operatorname{artificial~}^{30}$.

${ }^{25}$ Ver Reis 2001: 110-111.

${ }^{26}$ Freitas Soares descreveu o leite das mulheres, após o parto, como "mais soroso", sendo que só com o passar do tempo "se torna mais consistente, e nutriente".

27 Ver Pereira e Pita 1993: 459-460.

28 Cf. Memoria sobre a preferencia - Soares 1812: 20. Partindo da influência do génio do animal como forma de equilibrar os traços característicos dos indivíduos, sugeriu, em alternativa, ser também possível ter em conta o estatuto social. Assim, podia optar-se por dar o "Leite de cabras aos filhos de pais ricos, que pela maior parte são de hum temperamento melancolico, pouco activo, etc; e Leite de vaccas aos filhos de pais fortes, e que tem huma vida mais activa, e exercitada", cf. idem: 20.

${ }^{29}$ Cf. Memoria sobre a preferencia - Soares 1812: 25.

30 Refira-se, contudo, que recusou ter de se acordar o exposto durante a noite, para the dar leite, quando se encontrassem com amas externas. Referiu que quando eram acordados, ficavam "sobressaltados, e mamão com repugnancia, e sem necessidade, etc.". Porém, esta norma devia apenas aplicar-se à amamentação natural e a criação por amas. Nas grandes casas, "he indispensavel a regularidade", sendo que, "as crianças costumadas a mamar em horas reguladas, ordinariamente acordão a ellas pelo estimulo da fome, como acontece aos adultos, quando são regulares em suas comidas", Cf. Memoria sobre a preferencia - Soares 1812: 27. 


\begin{tabular}{|c|c|c|c|}
\hline Idade & $\begin{array}{l}\text { Quantidade máxima } \\
\text { recomendada para um dia }\end{array}$ & $\begin{array}{l}\text { Número de refeições } \\
\text { (por dia) }\end{array}$ & Horário das refeições \\
\hline $1 .^{\circ}$ mês & 1 libra de leite & \multirow[t]{2}{*}{8 refeições } & $\begin{array}{c}\text { 4:00; 7:00; 9:00; 11:00; 16:00; } \\
\text { 18:00; 20:00; 24:00 }\end{array}$ \\
\hline $2 .^{\circ}$ mês & 16 onças & & $\begin{array}{c}4: 00 ; 7: 00 ; 10: 00 ; 13: 00 \\
16: 00 ; 19: 00 ; 22: 00 ; 24: 00\end{array}$ \\
\hline $3 .^{\circ}$ mês & 1,5 libras de leite & \multirow[t]{2}{*}{6 refeições } & \multirow{2}{*}{$\begin{array}{c}4: 00 ; 7: 00 ; 11: 00 ; 16: 00 \\
20: 00 ; 24: 00\end{array}$} \\
\hline $4 .^{\circ}$ mês & 2 libras de leite & & \\
\hline $5 .^{\circ}$ mês & 3 libras de leite & 5 refeições & $\begin{array}{c}4: 00 ; 7: 00 ; 12: 00 ; 17: 00 \\
22: 00\end{array}$ \\
\hline
\end{tabular}

Tabela 1: Horários, refeições e quantidades previstas

Terminado o quinto mês de criação, iniciava-se um novo ciclo com a inclusão dos primeiros alimentos. Partindo do pressuposto que era essencial introduzir outro tipo de géneros durante a amamentação, para o crescimento e desenvolvimento vigoroso dos infantes, contrariando desse modo os que sustentavam a utilização exclusiva de leite por mais tempo, apresentou uma narrativa peculiar para a escolha das espécies a administrar ${ }^{31}$. Disse, pois, que se devia observar que "o homem he hum animal carnivoro, antesque chegue a ser granivoro e herviboro". Assim, sendo o sistema digestivo dos carnívoros mais frágil do que dos restantes, advogou a escolha de substâncias que detivessem "elementos e animalidade". A conclusão foi aferida pela observação direta dos estômagos dos diversos animais e do seu comportamento em estado selvagem:

[...] alguns carnivoros, como os animaes ferozes, e selvagens, tem as suas faculdades digestivas tão fracas, que até necessitão de se sustentar das carnes dos animaes vivas, e palpitantes, por gozarem de hum maior gráo de animalidade; e quando no estado social se lhes dão carnes mortas, elles perdem a maior parte da sua energia. Os mesmos animais graniveros, cujas forças digestivas são mais consideraveis, animalizão primeiro no seu estomago o alimento, que tem de dar a seus filhos, como observamos em muitas aves, e passaros; e só os filhos dos animaes ruminantes herbivoros, que tem quatro estomagos, commutão facilmente no começo da sua vida algumas substancias não animalisadas ${ }^{32}$.

${ }^{31}$ No caso de crianças não abandonadas, o autor sustentou que os primeiros alimentos podiam ser introduzidos logo após o primeiro ou o segundo mês. Esta diferença era o resultado da maior fragilidade física dos expostos, que se devia traduzir no recurso mais tardio de alimentos sólidos. Ver Memoria sobre a preferencia - Soares 1812: 28.

32 Cf. Memoria sobre a preferencia - Soares 1812: 29. Sobre este assunto, Freitas Soares registou ainda, "a mim sempre me agradou ver algumas Mãis no tempo da lactação mastigarem o pão, e carne para darem a seus filhos, optimo alimento até pela saliva que o acompanha; 
A alimentação dos expostos através da memória sobre a preferência do leite de vaccas (1812), de José Pinheiro de Freitas Soares (1769-1831)

Desse modo, rejeitou toda a dieta que não tivesse passado por qualquer processo que lhe permitisse ter parte dessa característica peculiar. Os processos adequados eram os da fermentação, "a qual dá huma vida quasi animal ás substancias vegetaes", ou a torrefação "pois ambas estas operações offerecem meios de decomposição" ${ }^{33}$. Como receita ideal recomendou a farinha de trigo preparada do seguinte modo:

Esta farinha se mette no forno logo depois que delle se tire o pão, e se deixa dessecar até que adquira huma côr amarellada, e nestas circumstancias se coze igualmente em agoa, e se mistura com o mesmo Leite mungido de fresco. A farinha assim torrada contém o principio solidificante, o carbonio, absorve os acidos do estomago, e não tendo passado por esta operação os produz, e faz desenvolver vermes ${ }^{34}$.

Em alternativa a essa receita, recomendou a cevada geminada ou a farinha de arroz, preparadas do seguinte modo:

[...] cevada germinada, torrada, em estado proximo a fazer a cerveja, da qual depois se faça cozimento para se misturar com Leite de vaccas, mungido de fresco [...] pois elle vai disposto pela fermentação, e torrefação a dar com facilidade os seus elementos ${ }^{35}$;

A farinha de arroz, da tapioca, da cevadinha de França, sendo antes brandamente torrada, e depois cozida em agoa, para se misturar com o Leite de vaccas fresco, pode tambem servir de alimento, em consistencia de caldo, que seja hum pouco grosso ${ }^{36}$.

Finalmente, as "papas de Camper". A sua confeção fazia-se a partir:

[...] do biscouto da flor da farinha, cozido em agoa, em vazilha de barro, que se deve mexer no tempo da coacção com huma colher de páo, ou de marfim, addicionandose-lhe, depois de bem cozido, hum pouco de assucar, e algum Leite de vaccas, que he melhor, sendo mungido de fresco ${ }^{37}$.

porém he necessario que ellas sejão sadias", cf. idem: 33. Mais adiante, voltou a frisar "Quando nascemos [...] somos logo carnivoros, só com a idade nos fazemos granivoros, e herbivoros; e portanto os succos das carnes são necessarios ás crianças; e só na velhice, quando a Natureza tem já tocado os limites da anamalidade, he que convem mais ao homem o regimen vegetal, unido porém sempre a huma porção de gelea animal", cf. idem: 34 .

33 Cf. Memoria sobre a preferencia - Soares 1812: 22.

34 Seguindo o texto, caso os infantes apresentassem "sinaes de flatulencia", devia-se "ajuntar alguns pós de canella, ou de gengibre com magnesia", cf. Memoria sobre a preferencia - Soares 1812: 32 .

35 Cf. Memoria sobre a preferencia - Soares 1812: 30.

${ }^{36} \mathrm{Cf}$. Memoria sobre a preferencia - Soares 1812: 30.

37 Cf. Memoria sobre a preferencia - Soares 1812: 31-32. 
A partir do oitavo mês, passava a ser permitido introduzir géneros próximos da carne. Tendo de ser sujeitos a processos semelhantes e não devendo arrefecer antes de serem ingeridos, sugeriu que se observasse a seguinte receita:

Tomem-se seis onças de vitella, com duas onças perto de carne de vacca [ou, em alternativa, um quarto de uma galinha nova] pize-se tudo, e mesmo os ossos [...] metta-se esta massa em hum pequeno vaso de barro, não vidrado, ou de prata, e lance-se-lhe depois em cima hum grande copo de agoa fervendo.

Terminado o procedimento, "deixe-se tudo, tapado o vaso, em digestão", ficando em breve "hum caldo muito doce". Com vista a complementar a receita com alguns elementos vegetais, princípio do que designou de "bem nutrir", "tomaremos huma pequena porção [...] deste caldo, e lançaremos sobre huma codea de pão torrado, e pizada, e lhe ajuntaremos hum pouco de assucar, e ás vezes huma pitada dos pós de canella". Concluiu: "eis aqui hum alimento muito proprio para as crianças" 38 .

A próxima alteração significativa decorria no $13 .^{\circ}$ mês, altura em que se devia proceder ao fim do consumo de leite. No entender do autor, a elevada mortalidade registada neste processo era consequência da transição brusca a que algumas crianças eram sujeitas. Assim, aconselhou que era indispensável seguir uma habituação progressiva de modo a que o desmame não fosse mais que o fim "do uso de hum dos alimentos das crianças, e não uma mudança total e repentina de seu modo de nutrição" ${ }^{39}$. Sobre o assunto, registou que no 13. mês, "o Leite das amas já tem pouca vitalidade", não sendo mais que "huma sorosidade salina, mal sagregada das Crianças", estando na origem das "aphtas, as colicas, e outras molestias" ${ }^{40}$

Nesta fase, a dieta devia ser animal e vegetal (dentro das receitas enunciadas). Sobre a preparação da carne, preferiu as "carnes de aniames novos, com exclusão dos que são velozes na carreira; pois os succos destas carnes são mais indigestos, e excedem os limites da animalidade das crianças”. Assim, "a vitella, a vacca, o carneiro, o frango, a gallinha, e outros volateis dão hum bom alimento" não pelo consumo direto da carne, que diz não se dever fazer ainda, mas sim "com os succos, ou geleas, que dellas se extrahem" ${ }^{41}$.

${ }^{38}$ Cf. Memoria sobre a preferencia - Soares 1812: 34.

39 Cf. Memoria sobre a preferencia - Soares 1812: 35.

40 "e por isto já mais eu aconselharei, que huma ama, acabada a primeira criação, faça segunda", Cf. Memoria sobre a preferencia - Soares 1812: 36. Os expostos que se mostrassem particularmente frágeis podiam constituir exceção ao desmame, concluído o seu $1 .^{\circ}$ ano de vida. Nestes casos, podiam manter-se sob sustento de leite por mais 6 ou 12 meses, ver idem: 36 .

${ }^{41}$ Estes sucos deviam extrair-se preferencialmente através das "carnes golpeadas, e mal assadas, tirados por expressaõ; poisque estes extractos animaes são mais restaurantes doque os obtidos pela ebullição". Caso as crianças mostrassem relutância em aceitar esta receita, sugeriu "branquear [os 
Como possíveis suplementos, referiu "as sopas de Leite com assucar; o bom pão molhado em ovos quentes com assucar; as sopas dos caldos de vacca, ou de galinhas, temperados com simplicidade" ou "as sopas do mel" que, por terem sido "animalizado já pelas abelhas" constituía uma ótima escolha ${ }^{42}$. Para bebida recomendou preferencialmente água fria com açúcar ${ }^{43}$.

Quanto à açorda, desaconselhou-a antes do fim do $2 .^{\circ}$ ano, em virtude "da manteiga, e do alho; que devem cançar estomagos ainda tenros, e delicados" 4 . Não encorajou igualmente que se dessem quaisquer "carnes gordas, como toucinho, as carnes defumadas, ensacadas, massas, pasteis, empadas”, bem como as farinhas não fermentadas, os caldos de hortaliças e outros vegetais grosseiros, o chá e o café, "as papas das farinhas não fermentadas, os caldos de hortaliças, e outros alimentos vegetaes, e grosseiros, dos quaes usão as mulheres do campo para as crianças desmammadas". Segundo o autor, a elevada mortalidade daqueles que eram criados nos campos devia-se, em parte, à introdução demasiado precoce das espécies supra apontadas ${ }^{45}$.

\section{Os utensílios e as práticas}

Uma das referências que melhor ilustra o ambiente único, quase caricato, dos interiores das grandes Rodas, advém do relato do qual se depreende que, uma das razões para a comum preferência das cabras, se devia à "facilidade de se poderem conduzir as cabras ás Cameras dos Expostos” permitindo "poderem arranjar[-se] [as cabras] sobre os berços das Crianças, a fim de mammarem mais commodamente". Segundo o autor, tal como já havia referido Pina Manique, era até possível notar uma "notavel satisfação" da parte dos animais, após servirem para esse propósito durante alguns dias ${ }^{46}$. Sobre essa prática, observou que não contestava que existiam vantagens em executar a amamentação diretamente das cabras. Contudo, pela grande necessidade de controlar a quantidade de leite ingerida, desaconselhou-a ${ }^{47}$.

alimentos] com hum pouco de leite", cf. Memoria sobre a preferencia - Soares 1812: 36.

${ }^{42}$ Referiu ainda a possibilidade se darem algumas "raizes, e grãos, como os nabos, as ervilhas, as lentilhas, cozendo-se em caldo de carnes, coando-se por expressão forte, e ajuntando-se-lhe o sal das Crianças, que he o assucar, e huns pós de canella”. Ainda, as frutas da época, dadas com reserva e preferencialmente cozidas, cf. Memoria sobre a preferencia - Soares 1812: 37.

43 "dada em sufficiente quantidade, e não em muita abundancia, ajuda a digestão, dilue os alimentos, e faz lançar com os excrementos os restos da materia nutritiva, que no estomago existirem em decomposição". Chegava a ser "huma bebida até muito util ás crianças convalescentes", cf. Memoria sobre a preferencia - Soares 1812: 38.

${ }^{44}$ Cf. Memoria sobre a preferencia - Soares 1812: 37.

${ }^{45}$ Cf. Memoria sobre a preferencia - Soares 1812: 38.

${ }^{46}$ Cf. Memoria sobre a preferencia - Soares 1812: 13.

${ }^{47}$ Ver Memoria sobre a preferencia - Soares 1812: 23. 
A título de exemplo, registou:

Nem se me opponha, como alguns pertendem, que as Crianças mam-
mando nas tetas das cabras, recebem o Leite com o calor natural, hum
leite animado, sem perda dos seus principios mais volateis, ganhando-se
ao mesmo tempo a secreção salival. Estas vantagens, he certo, dão a pre-
ferencia ao methodo natual pelo que respeita ás Mãis, e ainda ás Amas;
porém não pelo que respeita ás cabras, cujo Leite se affasta muito a todos
os respeitos da natureza do Leite de peito: quando pelos meios artitificiaes
tambem podemos obter as principaes vantagens ${ }^{48}$.

Não deixou de chamar a atenção para a importância de não deixar as crianças adormecer antes de finalizarem toda a amamentação, no caso de serem alimentadas pelas mães ou pelas amas, devido ao perigo de sufocarem ${ }^{49}$. No caso do leite de animais, se o exposto mostrasse sinais de fome após a ingestão da quantidade prescrita, podia dar-se uma côdea de pão ou, preferencialmente, "hum pequeno osso de carneiro com pouca carne". Sustentou, "os seus olhos [das crianças] se alegrarão com esta vista, a Natureza explica bem a sua necessidade, e por outra parte se lhes facilita a sahida dos dentes" ${ }^{50}$.

Sobre os utensílios utilizados, o texto permite conhecer várias modalidades. Desde a utilização de "uma colher de páo, de marfim, ou de prata", à utilização de "bonecas, feitas de algodão, ou de esponja, e forradas de panno de linho macio". Entre todas, o autor mostrou preferência pelos bules pois, estes não só possibilitavam retardar o arrefecimento precoce do leite, como também permitiam "aproveitar a secreção da saliva, liquido de muita importância para a digestão" e ainda, a possibilidade de evitar a exposição do leite ao ar, que levava a uma degradação mais rápida ${ }^{51}$.

No cuidado e rigor que pontua a obra, pode ler-se uma descrição meticulosa, sobre o formato e proporção adequadas para os bules e a forma correta de os usar. Como material, elegeu que fossem de vidro, ou de barro não vidrado, preferíveis aos de metal (particularmente cobre) que "accelérão a alteração do Leite". O bule devia ter o formato de "huma bexiga com o seu bojo, ou de hum bule" com duas aberturas. A superior devia ser larga e possível de fechar através de um encaixe com rosca e de forma segura. A segunda, lateral, devia posicionar-se na extremidade de "hum bico pouco comprido", sendo encerrada por uma esponja fina que devia ter uma forma circular por meio da utilização de uma pele fina. Essa pele devia ser trespassada por pequenos orifícios, de modo a tornar-se semelhante ao peito materno, quando apresentado às crianças ${ }^{52}$. Cada um desses bules devia ter a proporção adequada

\footnotetext{
${ }^{48}$ Cf. Memoria sobre a preferencia - Soares 1812: 23.

${ }^{49}$ Ver Memoria sobre a preferencia - Soares 1812: 21-22.

50 Cf. Memoria sobre a preferencia - Soares 1812: 39.

${ }^{51}$ Cf. Memoria sobre a preferencia - Soares 1812: 40-41.

${ }^{52}$ Ver Memoria sobre a preferencia - Soares 1812: 42.
} 
à quantidade de leite a ingerir, de modo a evitar o contacto com o ar, tanto quanto possível. Repetidamente, advogou que deviam ser bem lavados após todas as utilizações. A última vantagem residia na possibilidade de colocar os bules em água quente, podendo conservar-se o seu calor natural ${ }^{53}$.

Tendo consciência da importância de uma boa alimentação para o desenvolvimento saudável e robusto de todos os seres vivos, o autor terminou fazendo apologia da necessidade de tratar e cuidar bem das vacas e de atender à sua idade para que o leite extraído tivesse qualidade suficiente. Não constituindo tópico de relevo para o tema geral em análise, diga-se, brevemente, que defendeu a necessidade de proporcionar às vacas "vão pastar todos os dias aos campos, ou planices, aonde achem feno, e outras hervas" ou aos bosques, durante o inverno particularmente. Desse modo, "recebem hum bom alimento, respirão hum ar mais puro, fazem exercicio, o que tudo influe para darem Leite mais nutritivo, mais saudavel, e com mais vitalidade" ${ }^{54}$. Finalmente, referiu a necessidade de lhes dar água de qualidade e de as conservar limpas, com currais confortáveis e bem tratadas ${ }^{55}$.

\section{Considerações finais}

A obra em análise constitui um reflexo do primado das ciências médicas, tão evidente no século XIX. Ao mesmo tempo, a longa explanação remete para a dimensão do "problema dos expostos", particularmente nas grandes Rodas onde as condições eram, tantas vezes, aterradoras. Finalmente, as teorias que faziam assentar a riqueza dos Estados numa população numerosa e robusta colidiam com a realidade das Rodas acabada de descrever, à qual urgia procurar soluções que tardaram a chegar.

Noutra perspetiva, esse trabalho de Freitas Soares parte da primazia da experiência e da observação, na qual a maioria das instruções se defendeu com referências a casos práticos e análises conduzidas por autores Setecentistas, que provavam a veracidade das teses apresentadas. Contudo, é necessário

53 Ver Memoria sobre a preferencia - Soares 1812: 42-43. É possível detetar, aliás, uma clara explanação no sentido da importância de manter o leite à temperatura natural. Sobre a possibilidade de ferver o leite, nota-se que havia consciência que se permitia a sua conservação por mais tempo sem perder qualidade, "e nós ganhamos na separação de huma certa porção de ar, que a ebulição promove, o qual sempre accelera a sua decomposição”. Após problematizar bem o tópico, apoiou que se procurasse dar o leite logo após a sua extração e conservando a temperatura. Se não fosse possível, podia ferver-se, devendo ser utilizado apenas quando regressasse à temperatura natural, ver idem: 43-47.

${ }_{54}$ Cf. Memoria sobre a preferencia - Soares 1812: 49.

55 "He finalmente necessario conservar as vaccas no maior asseio: lavando-as, limpando-as, promovendo a limpeza dos curraes; fazendo-se renovar a miudo a sua cama de palha, ou de mato; poisque o asseio influe muito na economia da secreção do Leite. Igualmente devem ser tratadas com beneficencia; pois o máo tratamento, as pancadas, etc. manifestamente fazem mudar a qualidade do Leite", cf. Memoria sobre a preferencia - Soares 1812: 50. 
anotar que o autor não abandonou todos os paradigmas antigos, algo muito evidente na referência à teoria dos humores. Reconhecendo maior importância às ciências médicas, não recusou a importância desse paradigma para o bem-estar dos indivíduos. Essa referência remete para o caráter lento da alteração de paradigmas médicos e culturais e pela coexistência de modelos novos e velhos, não só entre autores contemporâneos, mas também na obra de alguns indivíduos, se considerados individualmente.

Finalmente, do ponto de vista alimentar, há conceções adequadas (como a consciência da progressão do leite materno ao longo da amamentação, a própria ideia da preferência do leite de vaca em relação ao do leite de cabra, aos efeitos deteriorantes da exposição ao ar ou do aquecimento repetido dos géneros, etc). Porém, muitas foram acompanhadas de recomendações menos adequadas ou completamente erradas (constitui exemplo flagrante o conselho de se darem ameixas aos recém-nascidos com vista à regularização do seu trânsito intestinal).

Ainda assim, a obra permite entrar no quotidiano das Rodas em múltiplas dimensões. Do ponto de vista do tema em análise, torna-se possível colher receitas, ter algum entendimento sobre rotinas que seriam seguidas (como a de colocar as crianças imediatamente sob os peitos das cabras), entender o que a medicina considerava mais saudável e menos adequado para a saúde, entre outros aspetos. É, por isso, um valioso contributo para a história da alimentação de toda a infância.

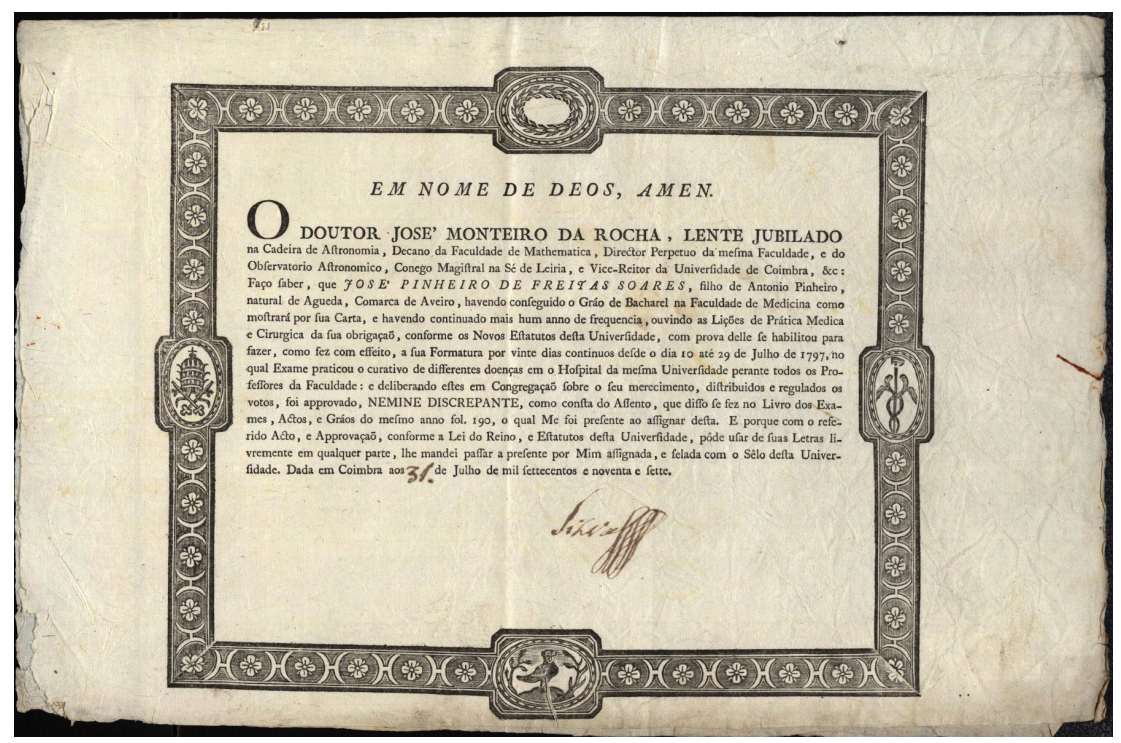

Anexo 1: Diploma de graduação de José Pinheiro de Freitas Soares em Medicina

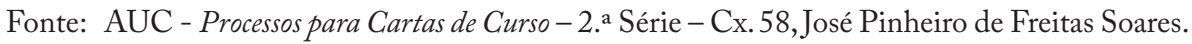




\section{REFERÊNCIAS}

\section{Fontes manuscritas}

\section{Arquivo da Universidade de Coimbra}

Coimbra, AUC, Certidões de Edade, 1772-1883, fl. 95 e 95v.

Coimbra, AUC, Matriculas, 1788/89-1796/97.

Coimbra, AUC, Processos para Cartas de Curso, 2. a Série, Cx. 58, José Pinheiro de Freitas Soares.

\section{Arquivo Distrital de Leiria}

Leiria, ADLra, Fiscalização e Fiscalidade. Expostos do Distrito de Leiria 1835 - 1877. orçamento do distrito para o ano económico de 1860 a 1861.

\section{Arquivo Histórico Municipal de Porto de Mós}

Porto de Mós, AHMPM, Atas de vereação da Câmara Municipal de Porto de Mós 18391842, 1842-1843, 1843-1848, 1848-1853, 1853-1857, 1857-1864, 1864-1875.

\section{Arquivo Nacional da Torre do Tombo}

Lisboa, ANTT, Registo Geral de Mercê, D. João VI, liv. 22.

Lisboa, ANTT, Tribunal do Santo Ofício, Inquisição de Lisboa, proc. 17193.

\section{Fontes impressas}

Siqueira, J. P. F. (1812), "Memoria sobre a creação, e vantagens do gado Cabrum em Portugal", in Memorias Economicas da Academia Real das Sciencias de Lisboa, para o adiantamento da Agricultura, das Artes, e da Industria em Portugal, e suas Conquistas, Lisboa, Typographia da Academia Real das Sciencias, 143-153.

Soares, J. P. de F. (1818), Tratado de Policia Medica, no qual se comprehendem todas as materias, que podem servir para organizar hum regimento de policia da saude, para o interior do reino de Portugal, Lisboa, Typographia da Academia Real das Sciencias.

Soares, J. P. de F. (1812), Memoria sobre a preferencia do leite de vaccas ao leite de cabras para o sustento das crianças, principalmente nas grandes casas dos expostos; e sobre algumas outras matérias, que dizem respeito á criação delles, Lisboa, Typographia da Academia Real das Sciencias.

\section{Estudos}

Abreu, L. (2013), Pina Manique, um reformador no Portugal das Luzes, Gradiva, Lisboa.

Braga, P. D., Braga, I. M. R. M. D. (2012), "Do leite à açorda. Para a história da alimentação infantil (séculos XVI-XIX)”, in M. M. L. de Araújo, A. C. Lázaro, A. Ramos, A. Esteves (coord.), O Tempo dos Alimentos e os Alimentos no Tempo, CITCEM, Braga, 149-168. 
Braga, I. M. R. M. D. (2001), Assistência, Saúde Pública e Prática Médica em Portugal: Séculos XV-XIX, Universitária, Lisboa.

Braga, I. M. R. M. D. (2011), “Fugindo dos 'Grilhões do Cativeiro’: Os Expostos Pretos e Pardos na Casa da Roda da Misericórdia de Lisboa (1780-1807)”, Revista de História da Sociedade e da Cultura 11: 224-248.

Fonseca, F. T. (2014, 2. a ed.), "A Dimensão Pedagógica da Reforma de 1772: Alguns Aspectos", in A. C. Araújo (coord.), O Marquês de Pombal e a Universidade, Imprensa da Universidade de Coimbra, Coimbra, 49-78.

Lopes, M. A. (2008), “A intervenção da coroa nas instituições de Protecção Social de 1750 a 1820", Revista de História e Teoria das Ideias 29: 131-176.

Lopes, M. A. (1984), “Os Expostos no Concelho de Meda em meados do século XIX”, Revista Portuguesa de História XXI: 119-176.

Lopes, M. A. (2000), Pobreza, Assistência e Controlo Social: Coimbra (1750-1850), Palimage, Viseu.

Lopes, M. A. (2010), Proteç̧ão Social em Portugal na Idade Moderna: Guia de Estudo e Investigação, Imprensa da Universidade de Coimbra, Coimbra.

Marcocci, G., Paiva, J. P. (2013), História da Inquisição Portuguesa 1536-1821, Esfera dos Livros, Lisboa.

Pereira, A. L., Pita, J. R. (1993), "Liturgia Higienista no século XIX. Pistas para um estudo", Revista de História das Ideias 14: 437-559.

Reis, M. F. (2001), Os expostos em Santarém: A acção social da Misericórdia (1691-1710), Cosmos, Lisboa.

Roque, J. L. (1982), Classes Populares no Distrito de Coimbra no século XIX (1830-1870), [s.n.], Coimbra.

Sá, I. G. (1992), “Abandono de Crianças, Infanticídio e Aborto na Sociedade Portuguesa Tradicional através das Fontes Jurídicas", Penélope 8: 75-89.

Sá, I. G. (1987), A assistência aos expostos no Porto: aspectos institucionais (1519-1838), [s.n.], Porto.

Sá, I. G. (1995), A circulação de crianças na Europa do sul: o caso dos expostos do Porto no século XVIII, Fundação Calouste Gulbenkian, Lisboa.

Silva, I. F. (1860/85), "José Pinheiro de Freitas Soares", in Dicionário Bibliográfico Português, Imprensa Nacional, Lisboa, tomo V e XIII.

Soares, K. C. (2015), "A Evolução da Assistência aos Expostos durante o Século XIX no Distrito de Leiria”, Fragmenta Histórica 3: 11-38.

Subtil, C. L., Viera, M. (2012), “Os Tratados de Polícia, fundadores da moderna saúde pública (1707-1856)”, Referência 7: 179-187. 